\title{
USE OF NOTCHED SMALL PUNCH TEST SPECIMENS FOR THE DETERMINATION OF FRACTURE PROPERTIES IN STRUCTURAL STEELS
}

\author{
G. Álvarez ${ }^{1 *}$, C. Rodríguez ${ }^{1}$, F.J. Belzunce ${ }^{1}$, T.E. García ${ }^{2}$ \\ ${ }^{1}$ SIMUMECAMAT research group. Escuela Politécnica de Ingenieros de Gijón. Universidad de Oviedo. \\ Campus Universitario de Gijón s/n, 33203. Asturias-España \\ ${ }^{2}$ Know-How Innovative Solutions S.L., C/ Juan de la Cierva, Nave 2, 33211. Asturias-España \\ *E-mail: galvarezdiaz4@gmail.es
}

\begin{abstract}
Various attempts have been made to determine the fracture toughness of metallic alloys by means of miniature tests, such as the small punch test, SPT. The use of notched SPT samples is the most convenient way to explore but as yet there is no consensus regarding the best methodology to apply. In this paper, longitudinally notched SPT samples of different steels were tested and the opening of the mouth of the notch was measured in the course of the tests, using interrupted tests to observe where the first crack appears in the most strained region of the notch region. Numerical analyses of the notch SPT tests were also performed in order to confirm the experimental results.

Comparing Crack Tip Opening Displacement (CTOD) results obtained using standard fracture toughness specimens with those derived from notched small punch tests, a procedure to obtain the value of the critical $C T O D, \delta_{I C}$, is proposed using the notch mouth opening value measured at the maximum punch displacement registered in the miniature test.
\end{abstract}

KEYWORDS: Fracture toughness, SPT, structural steels, CTOD.

\section{INTRODUCTION}

Fracture toughness is an important property in order to design structural steel components and structures assuming the possible presence of cracks or flaws. Such cracks can grow under applied external loads. Thus, it is absolutely necessary to control this risk. It is well known that fracture toughness is a material property that can be determined following certain standard procedures, such as the ASTM E1820 standard [1]. This standard uses quite large specimens (compact tensile, CT or single edge notch bending, SENB, specimens), making it crucial to have sufficient material available for testing [1].

Material extraction of such specimens from real components is not possible as it induces a local loss of the effective section and therefore the amplification of local stresses. On the other hand, there are sometimes small zones, such as heat affected zones in welds or coatings, that cannot be characterized using standard procedures due to their small dimensions. Miniature tests were developed to solve these problems. Among them, the small punch test (SPT) is one of the most popular. The SPT test has received great attention in recent years [2-11]. Its usefulness in determining the tensile properties of metallic alloys (yield strength, ultimate strength and even ductility) has already been proved. However, the use of this test to characterize other materials [12-14] and to determine other important properties, such as the ductile-to-brittle transition temperature and fracture toughness [15-18] is under permanent development. At present, there is a draft pre-standard document disseminated in Europe [19] which includes an annex with various proposals to obtain the fracture properties of metallic alloys, but no specific methodology has yet been defined.

The scientific community has been trying for some years to use the SPT to determine the fracture parameters of steels [20-22]. The first attempt consisted in correlating the fracture toughness from the maximum biaxial deformation after rupture, measured in a conventional SPT test [23,24]. One important advance was related to the introduction of a crack in the SPT specimen, as a stress concentrator. On the other hand, the inclusion of a crack in conventional SPT samples is not an easy task due to the low thickness of the specimen (typically $0.5 \mathrm{~mm}$ ). To solve this problem, the aforementioned European pre-standard document recommends the use of pre-notched SPT samples. Different kinds of notches have been studied by different research groups: surface circular notch [25,26], through thickness lateral notch [27,28] and surface longitudinal notch [29]. Several methodologies have also been proposed to obtain the fracture parameters of metallic materials using such notched samples. One of these proposals is based on determining the energy necessary to initiate a crack from the notch. This value is directly related to the energy parameters of fracture 
( $G$ or $J$ ), and this point can be identified as the point where the slope of the SPT load-punch displacement curve starts to decrease in zone III of a typical ductile plot [30]. Another possibility is the use of the opening of the mouth of the notch, called $C O D_{S P T}$ or $\delta_{S P T}$, following the same nomenclature used in standardized fracture toughness tests [27,29]. In any case, when comparing tests performed with notched SPT samples and standard fracture toughness tests important differences are observed. To begin with, the SPT sample is submitted to a biaxial load instead of a uniaxial load and the low thickness of the typical sample always produces a plain stress instead of plain strain state. Additionally, the small size of the specimens and the restricted space where the test takes place, make it difficult to measure the initiation and growth of cracks during the test. The use of interrupted tests could help to solve this problem.

A correlation between conventional fracture toughness critical parameters $\left(C T O D_{C}\right.$ and $\left.J_{I C}\right)$ and those obtained using small punch test samples with longitudinal notches, based on the opening of the mouth of the notch are analysed in this work. Interrupted SPT tests, SEM observations of the failed regions and a numerical analysis of the miniature tests are used to confirm the results obtained.

\section{MATERIALS AND METHODS}

\subsection{Materials}

Four different structural steels were used in this research. S355 structural steel has a ferritic-pearlitic microstructure (Figure 1a). H8 steel is mainly used in the naval sector and has a bainitic microstructure (Figure 1b). CrMoV steel is employed for the manufacture of pressure vessels in the petrochemical sector and has a microstructure composed of tempered bainite and martensite (Figure 1c). Finally, WM steel is the weld metal used to weld CrMoV steel. It has a fine acicular low-tempered bainitic microstructure (Figure 1d). The chemical compositions of the four steels are shown in Table 1.
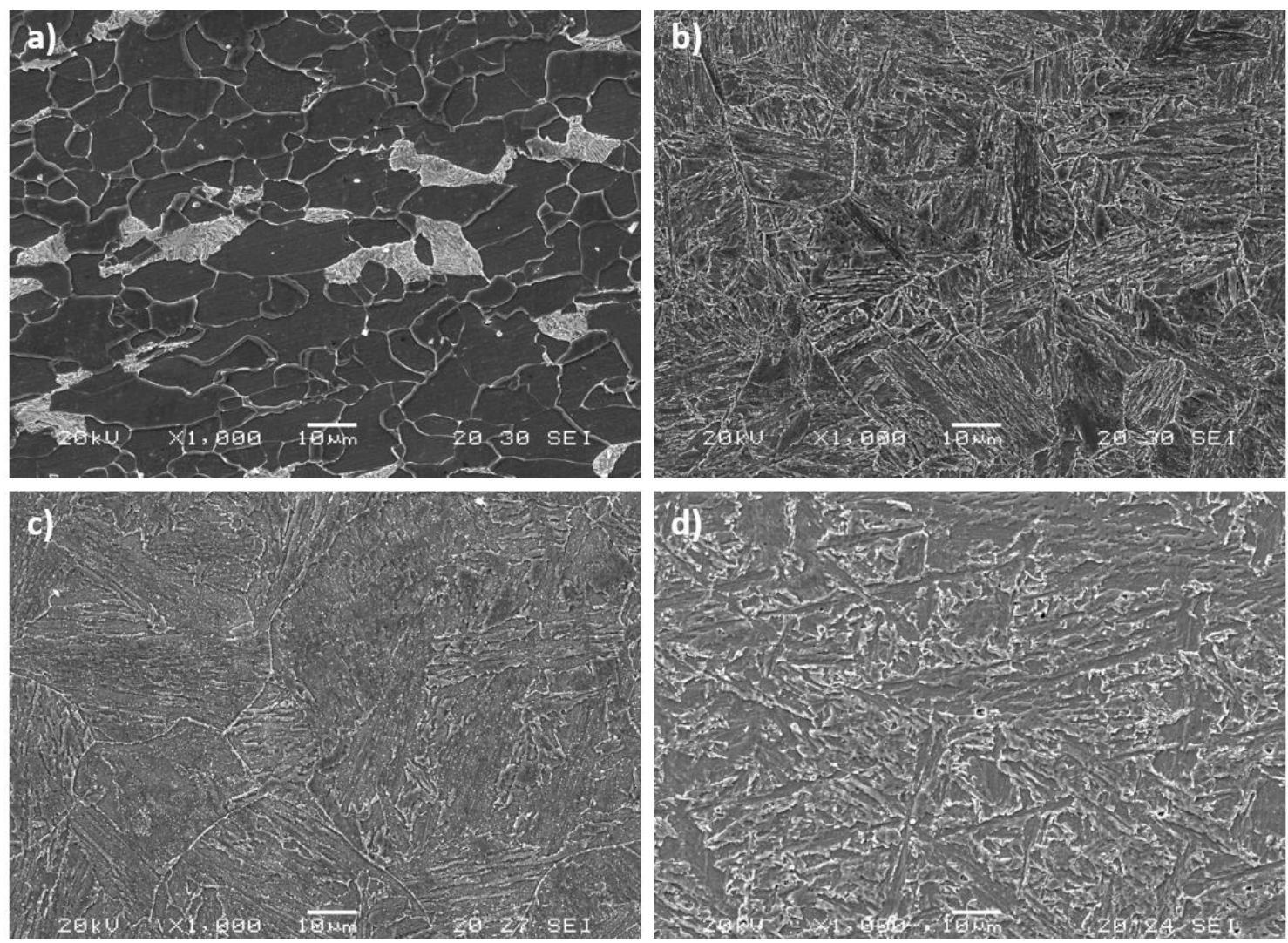

Figure 1. Microstructure of the steels. a) S355; b) CrMoV; c) H8; d) WM

Table 1. Chemical composition of steels (weight \%)

\begin{tabular}{cccccccc}
\hline Material & $\mathrm{C}$ & $\mathrm{Si}$ & $\mathrm{Mn}$ & $\mathrm{Cr}$ & $\mathrm{Mo}$ & $\mathrm{V}$ & $\mathrm{Ni}$ \\
\hline S355 & 0.13 & 0.26 & 0.8 & 1.58 & 0.05 & 0.00 & 0.25 \\
CrMoV & 0.15 & 0.09 & 0.52 & 2.17 & 1.06 & 0.31 & 0.19 \\
H8 & 0.15 & 0.09 & 0.25 & 1.58 & 0.55 & 0.05 & 3.05 \\
WM & 0.08 & 0.04 & 1.08 & 2.28 & 0.93 & 0.24 & 0.03 \\
\hline
\end{tabular}


Table 2 shows the tensile properties of the steels according to the UNE-EN ISO 6892-1 standard [31]: yield strength, $\sigma_{Y S}$, ultimate strength, $\sigma_{u}$, and elongation, $A$. The hardening coefficient, $n$, and the constant, $k$, were also calculated assuming a potential law to describe the plastic behaviour of the steels.

Table 2. Tensile properties of the steels

\begin{tabular}{cccccc}
\hline Material & $\sigma_{Y S}(\mathrm{MPa})$ & $\sigma_{u}(\mathrm{MPa})$ & $A(\%)$ & $n$ & $k(\mathrm{MPa})$ \\
\hline S355 & $386 \pm 1$ & $472 \pm 2$ & $32 \pm 0.14$ & $0.189 \pm 0.006$ & $803 \pm 21$ \\
CrMoV & $587 \pm 19$ & $700 \pm 16$ & $20 \pm 0.14$ & $0.107 \pm 0.007$ & $1019 \pm 16$ \\
H8 & $790 \pm 8$ & $857 \pm 10$ & $21 \pm 0.51$ & $0.067 \pm 0.007$ & $1339 \pm 35$ \\
WM & $1019 \pm 21$ & $1120 \pm 1$ & $17 \pm 0.11$ & $0.079 \pm 0.005$ & $1486 \pm 16$ \\
\hline
\end{tabular}

\subsection{Experimental tests}

\subsubsection{Standard procedure to CTOD - R curves determination}

Fracture toughness tests were carried out using three-point bending SE(B) standard specimens. The specimen dimensions were $50 \times 25 \times 250 \mathrm{~mm}^{3}$. They were fatigue pre-cracked at room temperature with an $R=0.1$ ratio, until obtaining a crack length-to-width ratio, $a / W \cong 0.5$ and were subsequently side-grooved to obtain a final net thickness, $B_{N}$, of $20 \pm 0.15 \mathrm{~mm}$. The CTODs values were calculated using equation 1 , where $K_{i}$ is the actual stress intensity factor; $E$ is the elastic modulus; $v$ is Poisson's ratio; $r_{p}$ is the plastic rotation factor, which was taken as 0.44 , according to the ASTM E1820 standard [1]; $\sigma_{Y S}$ is the yield strength of the steel; $v_{p l i}$ is the crack mouth plastic opening displacement $(C M O D)_{\mathrm{pl}}$; and $a_{i}$, the actual crack length, which was calculated using the partial unloading compliance technique. The sub-index $i$ represents different stages in the course of the test.

$$
\delta_{i}=\delta_{i}^{e l}+\delta_{i}^{p l}=\frac{K_{i}^{2} \cdot\left(1-v^{2}\right)}{2 \cdot \sigma_{Y S} \cdot E}+\frac{r_{p} \cdot\left(W-a_{i}\right) \cdot v_{p l_{i}}}{r_{p} \cdot\left(W-a_{i}\right)+a_{i}}
$$

Two representative values can be obtained from the $C T O D-R$ curves (CTOD versus crack growth, $\Delta a$ ). The first one is the $C T O D$ value corresponding to the onset of crack growth, $\delta_{i n i}$, which was determined at the point where the $\delta$-curve separated from the blunting line $\left(\delta=M_{\delta} \cdot \Delta a\right.$ where $M_{\delta}$ value is 1.4 ) and the second one is the value of the $C T O D$ corresponding to a stable crack growth of $0.2 \mathrm{~mm}, \delta_{I C}$. Figure 1 shows a standard $C T O D-R$ curve and the location of these two points.

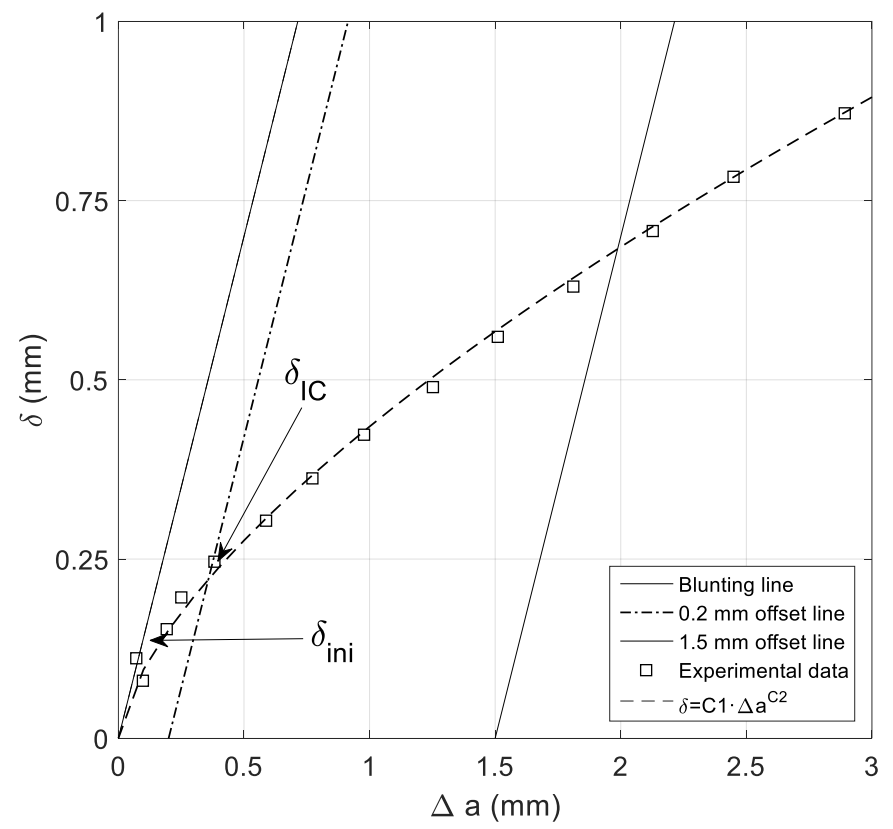

Figure 1. Location of $\delta_{\text {ini }}$ (crack growth initiation) and $\delta_{I C}$ (crack growth of $0.2 \mathrm{~mm}$ ) in a $\delta$-R curve

\subsubsection{Small Punch Test performed with notched samples}


Figure 2 shows the standard SPT device used, which consists of a hemispherical-head punch with a diameter of $2.5 \mathrm{~mm}$, a lower die hole with a diameter of $4 \mathrm{~mm}$ and a $0.2 \mathrm{~mm}$ chamfer edge. Standard SPT squared specimens (10x10x0.5mm) were also used, but provided by a longitudinal semi-circular notch with a depth, a, of $0.15 \mathrm{~mm}(a / t=0.3)$, which was machined with a micro-drilling machine (Figure $2 \mathrm{a})$. The load was applied using a mechanical testing machine equipped with a load cell of $5 \mathrm{kN}$ capacity and the punch displacement was measured with a COD extensometer. All the tests were performed in laboratory conditions under a displacement rate of $0.2 \mathrm{~mm} / \mathrm{min}$.

Several SPT tests were interrupted after attaining different displacement values, and the samples were then examined under the scanning electron microscope (SEM). The width of the notch was measured before the start of the tests and after test interruption. These measurements were taken at the maximum strained region of the sample (see Figure $12 \mathrm{~b}$ ).

a)
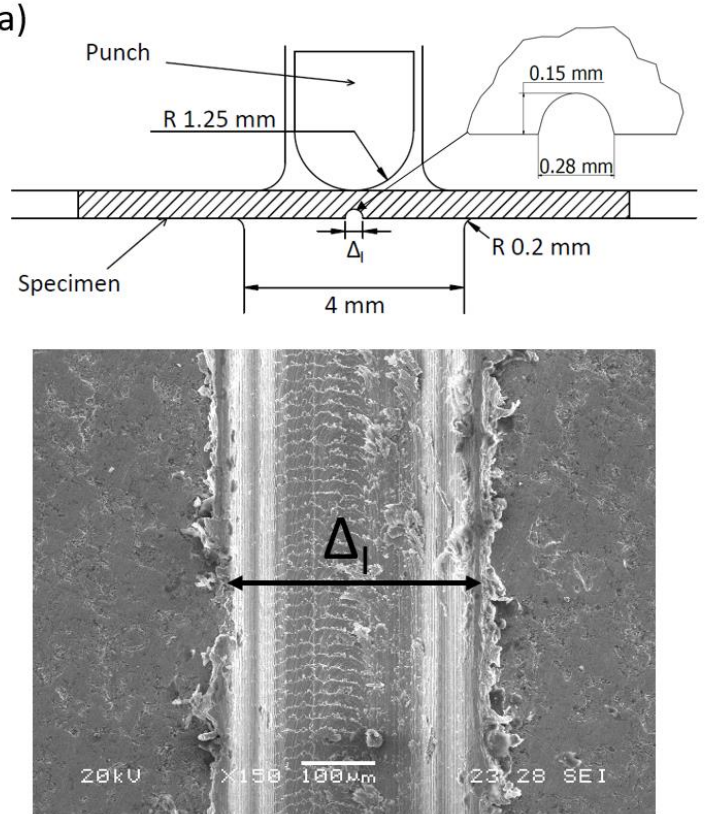

b)
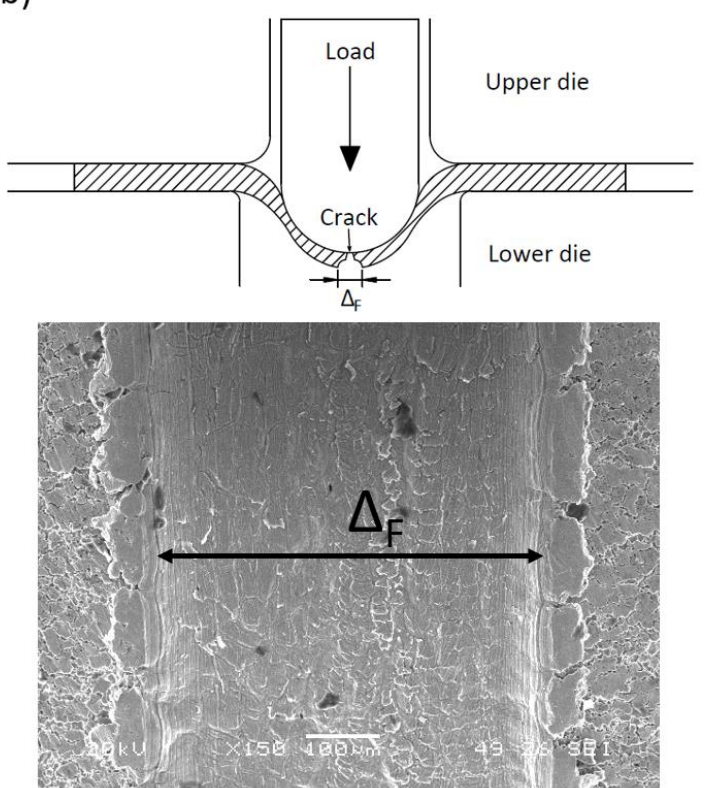

Figure 2. SPT device testing a notched specimen. a) Before the start of the test; $b$ ) Test once interrupted

The difference between the notch width measured at the beginning, $\Delta_{I}$ (Figure 2a), and at the end of the interrupted test, $\Delta_{F}$ (Figure $2 \mathrm{~b}$ ), was called $\delta_{S P T}$, as indicated in equation 2.

$$
\delta_{S P T}=\Delta_{F}-\Delta_{I}
$$

The interrupted specimens were also completely cracked into two parts using liquid nitrogen, in order to analyse the fracture surfaces and differentiate between ductile failure (stable crack growth that took place during the SPT test) and brittle failure (breakage in liquid nitrogen).

\subsection{Numerical simulation of the SPT tests}

In order to clarify the behaviour of the steel during the SPT test, numerical simulations were performed, using the Abaqus / Standard v6.13 software. Due to the presence of the notch, it was necessary to use a 3D model, as shown in Figure 3. The symmetry of the specimen allows a simplification of the model, thus working with only a quarter of it. The specimen model had 44400 nodes and C3D8 type elements. A refined mesh was used in the notch area, where the highest strain was expected. The rest of the elements used in the test, upper matrix, lower matrix and punch were modelled as rigid elements. The boundary conditions applied to the rigid elements were fixed displacements in all directions, except on the vertical axis in the case of the punch. A friction interaction between the dies and the specimen was also established with a friction coefficient, $\mu=0.1$ [32]. The notch opening, $\delta_{S P T}$, was measured as explained in Figure 3 (equation 2).

Two theoretical materials were also modelled, assuming bilinear elasto-plastic behaviour, to get the relationship between the notch opening and the displacement of the punch as a function of the mechanical 
properties of the material and of the thickness of the specimens. The mechanical properties of these theoretical materials are shown in Table 3

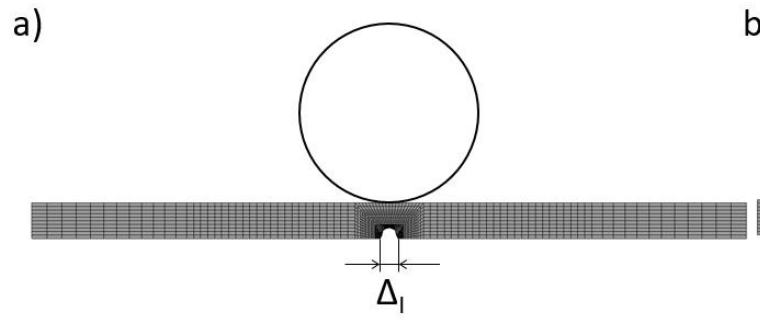

b)
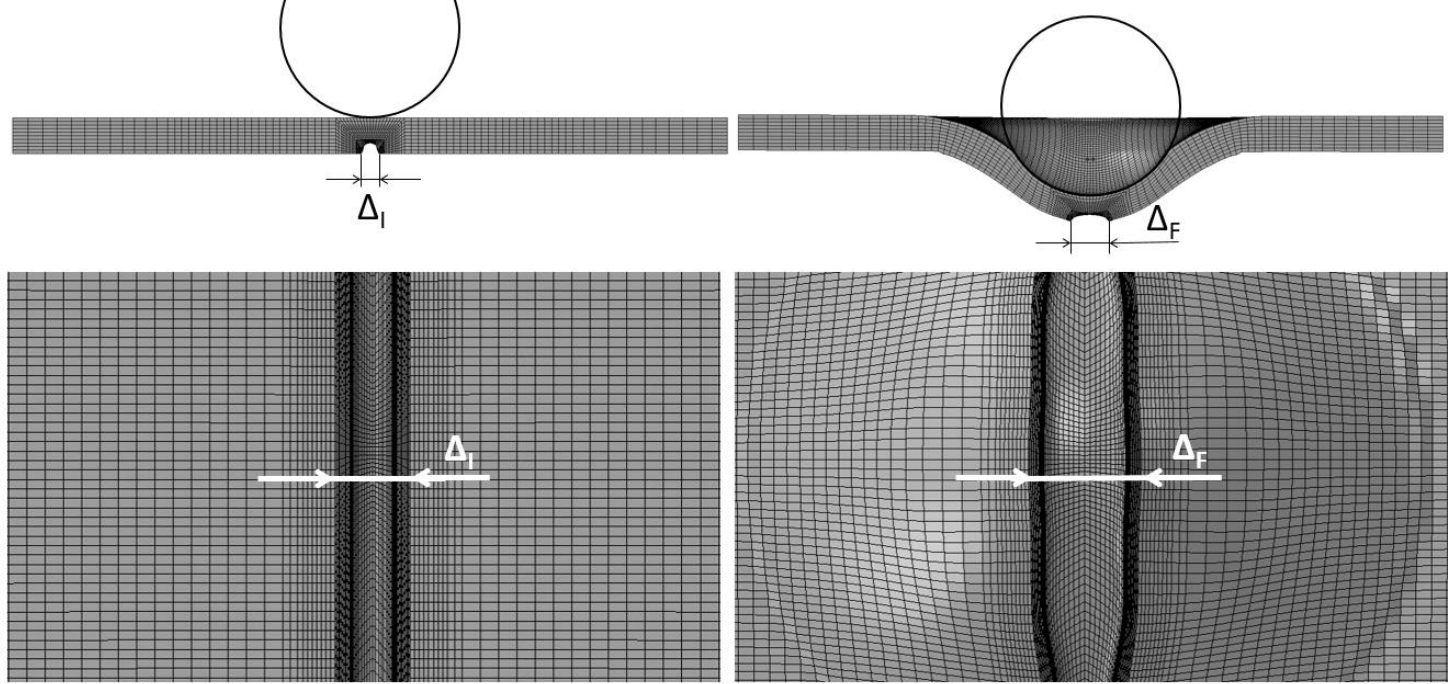

Figure 3. SPT model and mesh

Table 3. Mechanical properties of the theoretical materials

\begin{tabular}{cccc}
\hline Material & $\sigma_{y}(\mathrm{MPa})$ & $\sigma_{u}(\mathrm{MPa})$ & $\varepsilon_{u}(\mathrm{~mm} / \mathrm{mm})$ \\
\hline Material 1 & 400 & 600 & 0.2 \\
Material 2 & 1200 & 1800 & 0.2 \\
\hline
\end{tabular}

As no damage model has been introduced in the simulation, the difference between the numerical curves and the experimental ones will indicate the beginning of the damage in the notch region of the stressed specimen (moment in which the aforementioned curves separate).

\section{RESULTS AND DISCUSSION}

3.1 Standard fracture toughness tests

Figure 4a shows the $\delta$ - $R$ curves obtained with S355, CrMoV and H8 steels using SENB specimens. All three steels have ductile behaviour with stable crack growth. WM steel on the other hand, had brittle behaviour and its representative load - CMOD curve is presented in Figure 4b.

a)

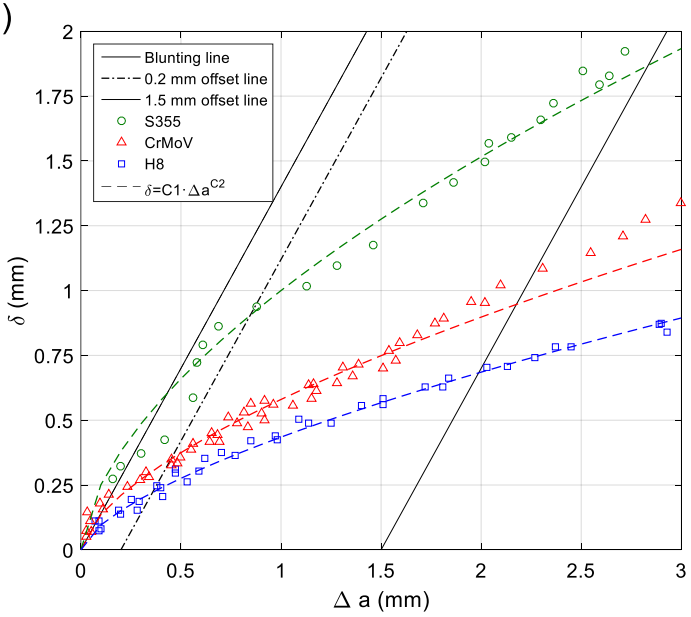

b)

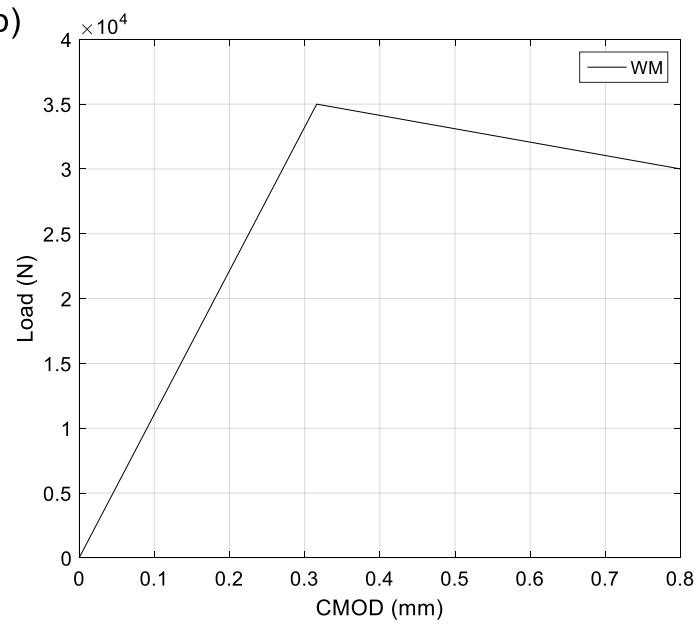

Figure 4. Experimental $\delta-R$ curves. a) Ductile steels; b) Brittle steel (WM) 
Table 4 shows the CTOD results obtained with the conventional tests performed according the ASTM E1820 standard $\left(\delta_{i n i}\right.$, and $\delta_{I C}$, see Figure 1$)$, along with the $\mathrm{J}_{\text {Ic }}$ obtained in the same test.

Table 4. Fracture toughness results obtained using standard specimens

\begin{tabular}{cccc}
\hline Material & $\delta_{\text {ini }}^{\text {standard }}(\mathrm{mm})$ & $\delta_{I C}^{\text {standard }}(\mathrm{mm})$ & $J_{I C}\left(\mathrm{~kJ} / \mathrm{m}^{2}\right)$ \\
\hline S355 & $0.750 \pm 0.093$ & $0.900 \pm 0.087$ & $750 \pm 20$ \\
CrMoV & $0.210 \pm 0.021$ & $0.417 \pm 0.022$ & $555 \pm 19$ \\
H8 & $0.150 \pm 0.008$ & $0.240 \pm 0.022$ & $450 \pm 15$ \\
WM & $0.008 \pm 0.000$ & $0.008 \pm 0.000$ & $22^{*} \pm 5$ \\
\hline
\end{tabular}

*Brittle material, calculated from $K_{I C}$, using the following expression, $J_{I C}=K_{I C}^{2} \cdot\left(1-v^{2}\right) / E$

\subsection{SPT tests}

Figure 5 shows the SPT load-punch displacement curves experimentally obtained with all the steels. The numbers beside the squares mark the successive experimental SPT tests that were interrupted, while maximum loads are indicated as fully shaded squares in the same figure. Points marked with circles correspond to locations where the experimental and numerical curves began to diverge (this specific point can also be seen in Figure 6b.). In addition, in the case of the S355 steel, another interrupted point corresponding to a maximum of the punch displacement was also marked once the maximum load (point 9) was surpassed. With the other three steels, complete failure always took place at the maximum load.

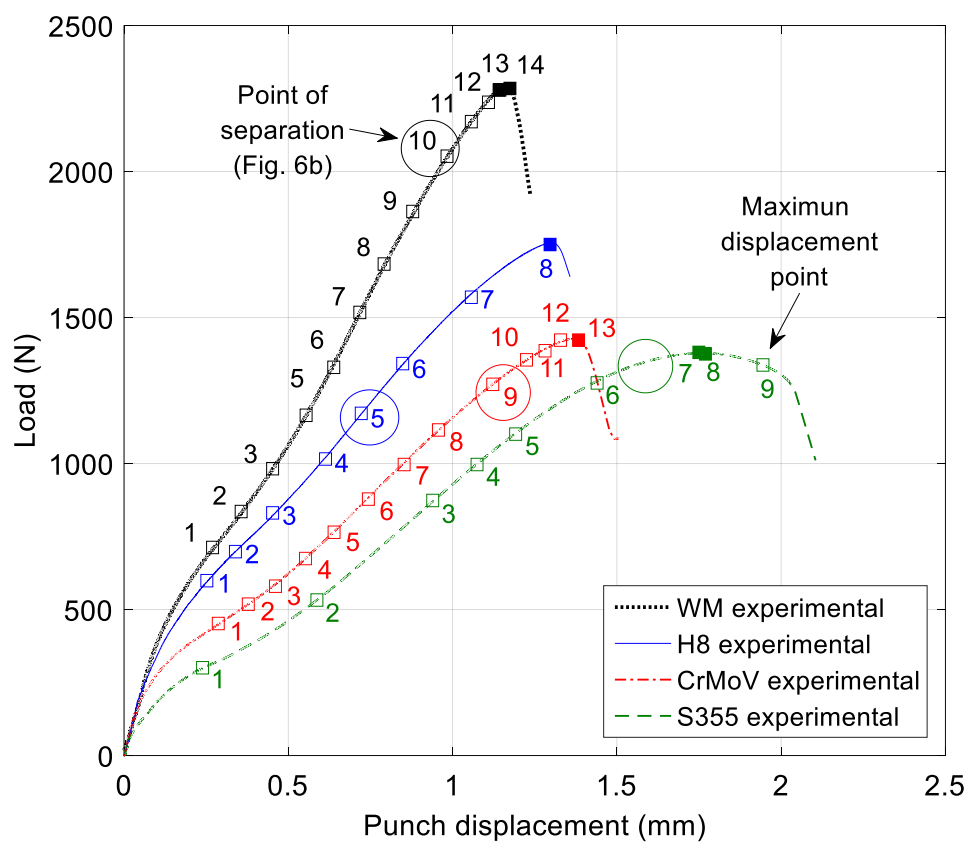

Figure 5. Experimental SPT load - punch displacement curves

Figure 6 a shows the crack opening, $\delta_{S P T}$, represented against the punch displacement, $d$, obtained by numerical simulation with the four steels and also with the two theoretical materials (see Tables 2 and 3 ). In the latter case, the effect of different sample thicknesses was also included (it was varied between 0.475 $\mathrm{mm}$ and $0.500 \mathrm{~mm}$, which is the typical thickness range of the experimental SPT samples). It is worth noting that the evolution of the $\delta_{S P T}$ with the punch displacement is very similar in all the cases until the punch reaches a displacement of $1 \mathrm{~mm}$. Then, it is possible to consider this $\delta_{S P T}-d$ relationship unique for any steel and thickness, at least in the range of those analysed in this work. Under displacements larger than $1 \mathrm{~mm}$, the curves of the different steels begin to diverge, but only slightly.

The S355 $\delta_{S P T}-d$ numerical curve is now taken as a master curve as it is the steel that showed the greatest punch displacement in the experimental tests and the highest fracture toughness in the conventional tests. Figure $6 \mathrm{~b}$ shows the $\delta_{S P T}-d$ experimental values determined in the interrupted tests for the four analysed steels. The experimental results follow the numerical ones until a certain point of the curve, separating from this point on (these points are indicated by a circle in Figures 5 and $6 \mathrm{~b}$ ). Therefore, these points represent the location of crack initiation in the notch region of the different steel samples. 
a)

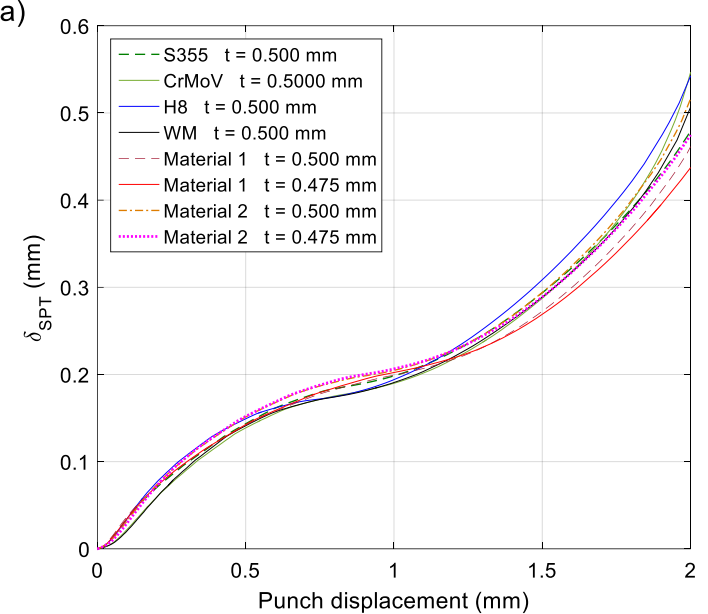

b)

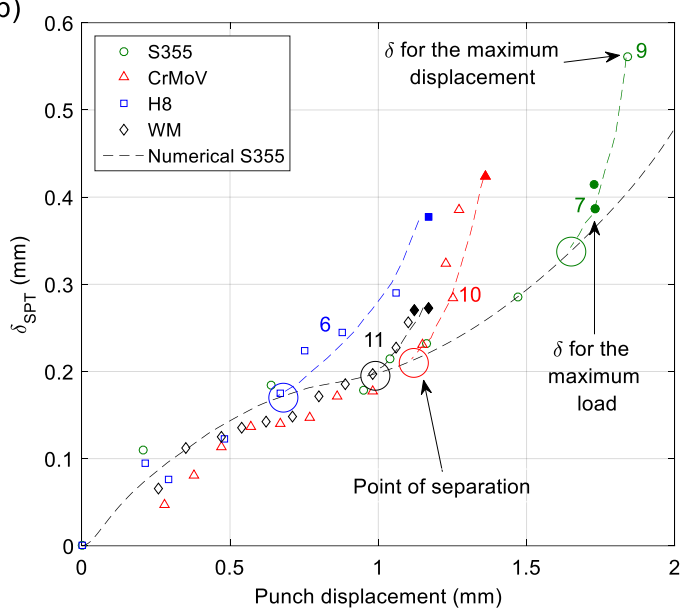

Figure 6. $\delta_{S P T}-$ Punch displacement curves. a) Numerical results; b) Experimental results

Based on these observations, the value of $\delta_{\mathrm{SPT}}$ at crack initiation (point at which the numerical and experimental curves separate), and the points of complete failure (at the maximum load in the case of the three steels with higher strength, and at the maximum punch displacement for the more ductile S355 steel) were calculated. Table 5 shows the obtained results.

Table 5. Experimental $\delta_{S P T}$ results (at crack initiation, at maximum load and at maximum punch displacement)

\begin{tabular}{cccc}
\hline Steel & $\delta_{\text {ini }}^{S P T}(\mathrm{~mm})$ & $\delta_{P \max }^{S P T}(\mathrm{~mm})$ & $\delta_{d \max }^{S P T}(\mathrm{~mm})$ \\
\hline S355 & 0.27 & 0.39 & 0.56 \\
CrMoV & 0.19 & 0.42 & 0.42 \\
H8 & 0.17 & 0.38 & 0.38 \\
WM & 0.19 & 0.27 & 0.27 \\
\hline
\end{tabular}

In order to establish a relationship between the CTODs determined using standard specimens and $\delta_{S P T}$, both parameters were represented in Figures 7 and 8. A very good correlation was obtained for $\delta$ at crack initiation (Figure 7a) and also for the critical CTOD, $\delta_{I C}$ when a maximum punch displacement criterion was used to evaluate the SPT results (Figure 8b). On the other hand, according to results shown in Figures $7 \mathrm{~b}$ and $8 \mathrm{a}$, the $\delta_{S P T}$ value obtained at maximum load does not have a good correlation with any standard $\delta$ value.

a)

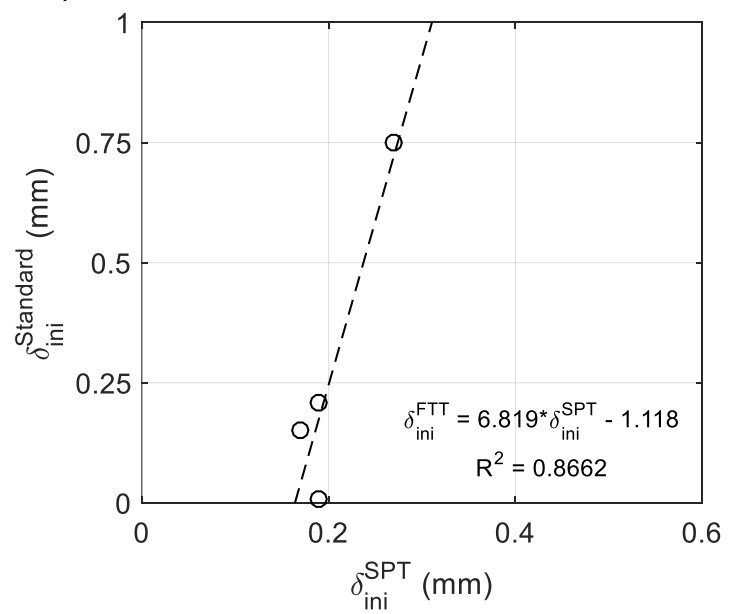

b)

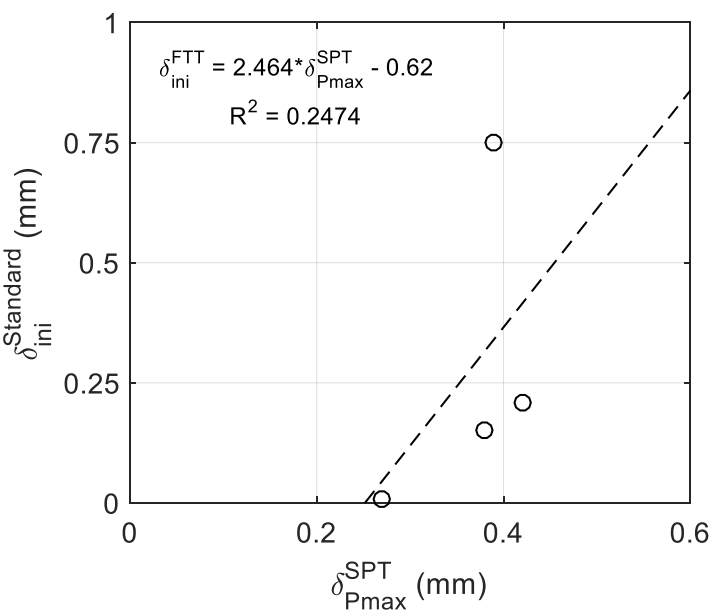

Figure 7. Experimental correlation results between standard $\delta_{\text {ini }}$ and the $\delta$ value obtained by means of SPT; a) at crack initiation; b) at maximum load 
a)

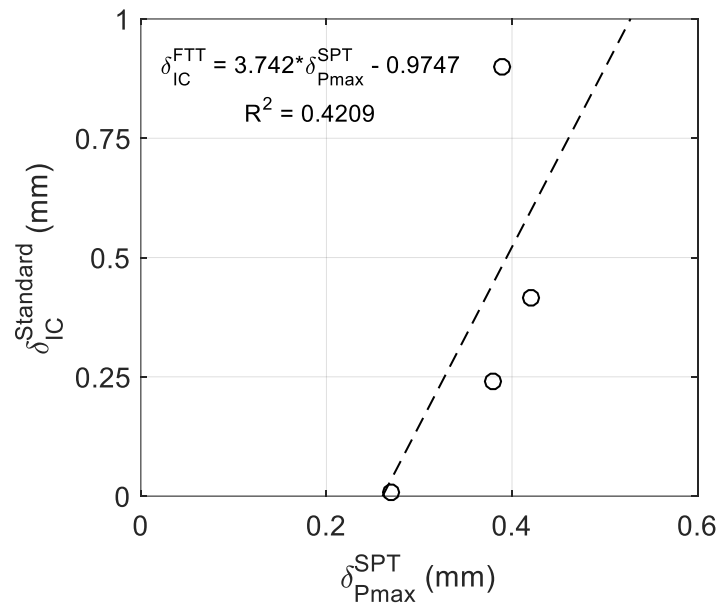

b)

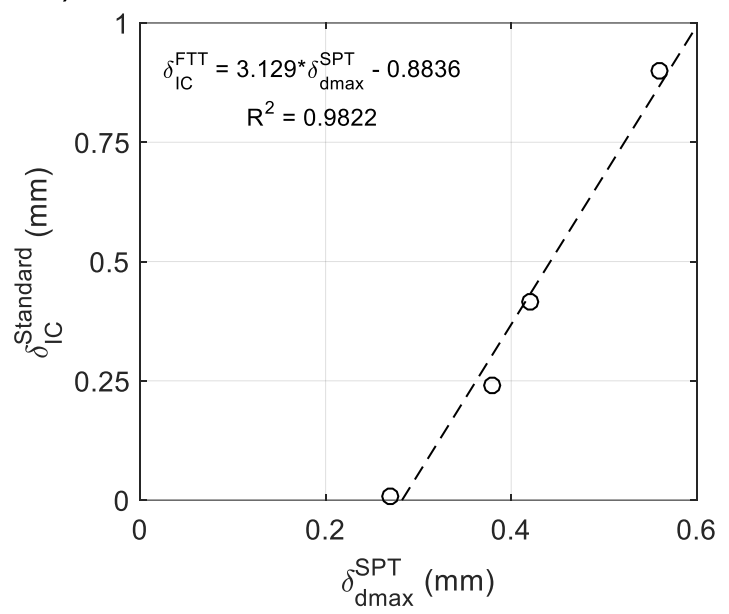

Figure 8. Experimental correlation results between standard $\delta_{I C}$ and the $\delta$ value obtained by means of SPT; a) Maximum load; b) Maximum displacement

As mentioned above, it is possible to establish a correlation between the CTOD obtained at the maximum punch displacement using the SPT (with the aforementioned sample geometry) and that calculated from the standard fracture toughness test. The following expression was obtained from the data regression shown in Figure 8b.

$$
\delta_{I C}=3.13 \cdot \delta_{d \max }^{S P T}-0.88
$$

The relationship between $C T O D$ and the $\mathrm{J}$ fracture toughness is also well known, equation 4 [1], where $J$ is the fracture toughness (in $\left.\mathrm{kJ} / \mathrm{m}^{2}\right) ; m$ is a constant that depends of the geometry of the specimen, whose value varied between 1 and 2 ; and $\sigma_{Y S}$ is the yield strength of the material.

$$
J=m \cdot \sigma_{Y S} \cdot \delta
$$

Substituting $J$ and $\delta$ with the critical parameters, $\mathrm{J}_{\mathrm{IC}}$ and $\delta_{I C}$ respectively and taking also into account equation 3, gives:

$$
J_{I C}=m \cdot \sigma_{Y S} \cdot\left(3.13 \cdot \delta_{d \max }^{S P T}-0.88\right)
$$

SEM observations of the notch region of the SPT samples corresponding to the interrupted tests were performed in order to confirm the accuracy of the previously exposed relationships. Figure 9 shows the appearance of the strained notch region once experimental and numerical curves separate. The images correspond to the samples where cracks are first visible on the notch surface; all of them were located very close to the point where experimental and numerical curves separate. Crack extension is seen to be very dependent on the type of steel tested. Some of the cracks are not easily distinguishable from machining defects. For this reason, and to clarify whether the first crack really appears at the point indicated in Figure 5 and $6 \mathrm{~b}$, these samples (interrupted SPTs specimens) were submerged in liquid nitrogen and then broken. This gave a fracture surface with three different regions: the notch, the stable crack growth, which took place during the SPT test, and the final brittle failure at low temperature. Figures 10 and 11 show the failure surface appearance of S355 and WM steels (the steels with the highest and lowest fracture toughnesses respectively). In the case of S355 steel, a stable crack propagation region characterized by a ductile micromechanism (microvoids coalescence) is clearly visible. The extension of this region is between 50 and $100 \mu \mathrm{m}$, demonstrating that first crack appeared just before point 7 in the plot shown in Figure 5 (no crack was seen in the notch surface of samples whose tests were interrupted before this one). A similar result was also obtained with the WM steel (Figure 11), where the first cracks appeared just before point 10 in Figure 5. 


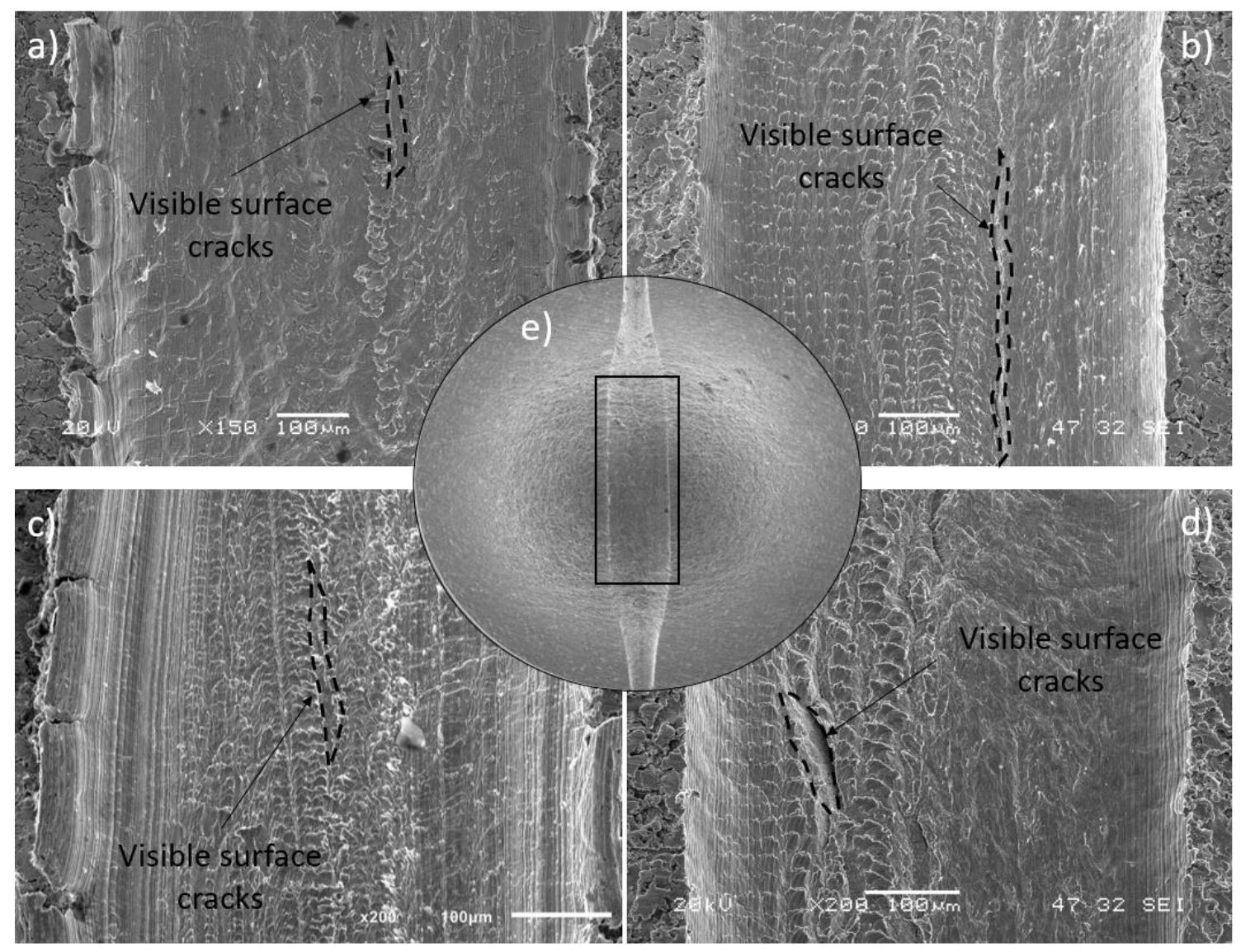

Figure 9. SEM vision of the notch area corresponding to the interrupted SPT specimens. a) S355 (point 7); b) CrMoV (point 10); c) H8 (point 6); d) WM (point 11); e) General view of the samples locating the enlarged region. See Figure 5 to locate the samples in the SPT load-punch displacement curves

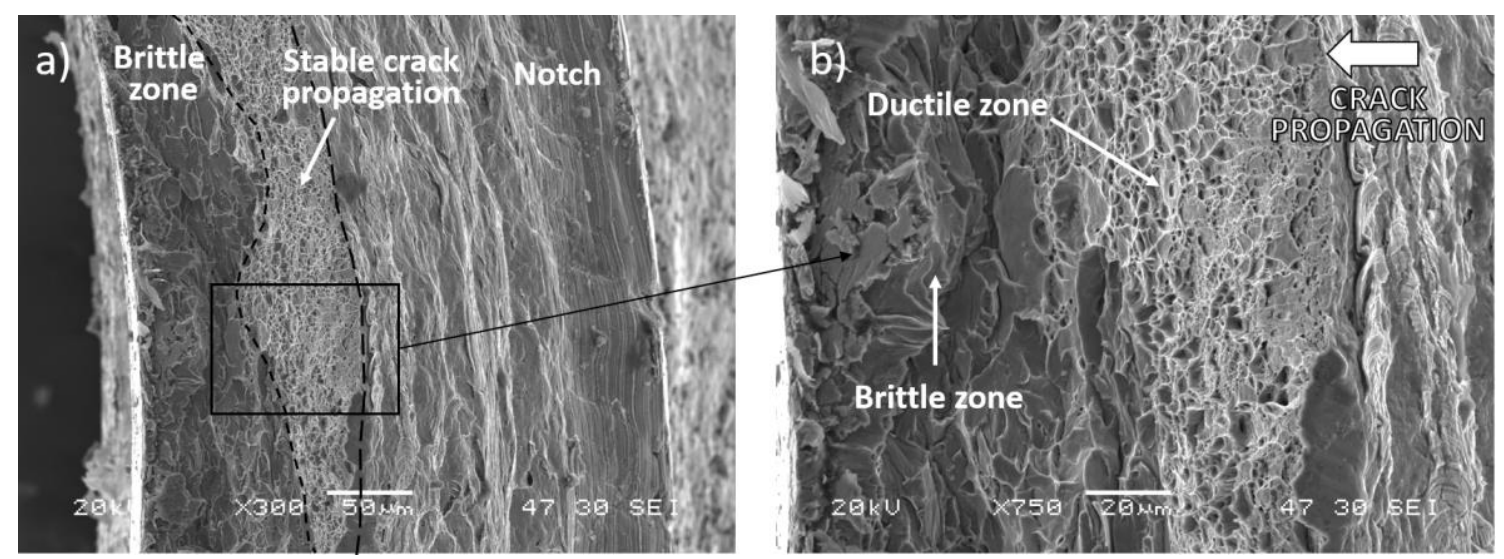

Figure 10. Failure surface of S355 interrupted SPT specimen corresponding to point $7(\delta=0.415 \mathrm{~mm})$ after complete break in liquid nitrogen. a) General view; b) Detail of the different failure micromechanisms in the middle region of the specimen. 

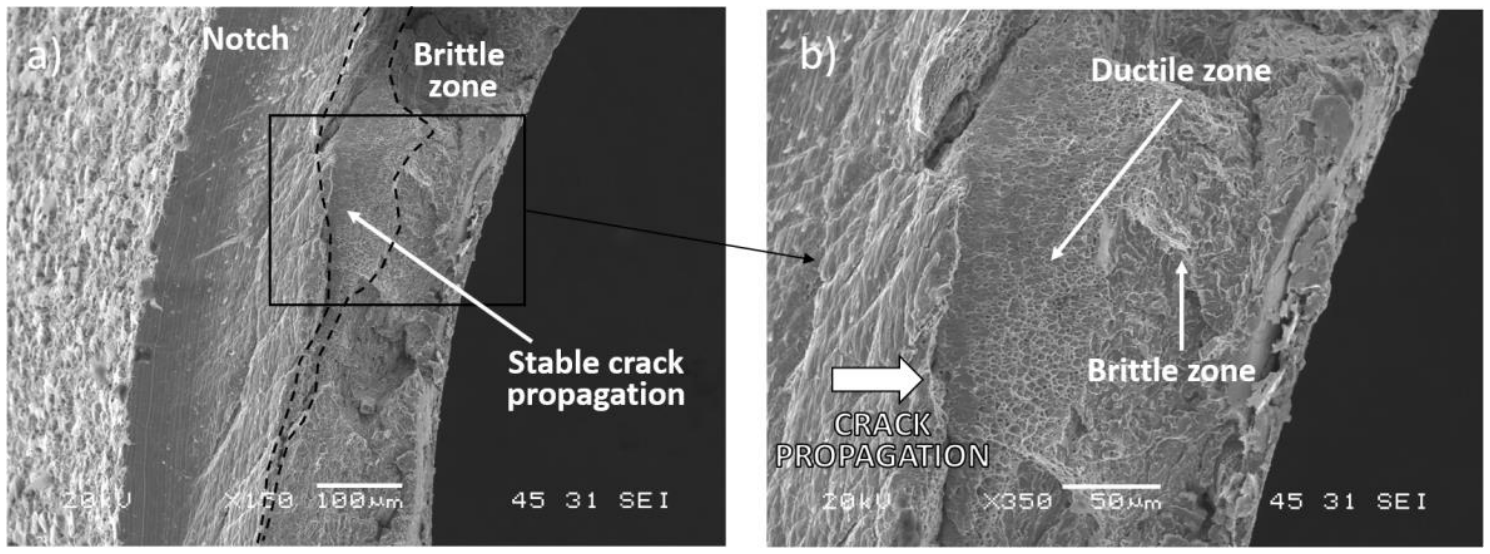

Figure 11. Failure surface of the WM interrupted SPT specimen corresponding to point $10(\delta=0.256$ mm) after complete break in liquid nitrogen. a) General view; b) Detail of the different failure micromechanisms in the middle region of the specimen.

Another important point to consider is the location of the first crack. By means of the numerical model (Figure 3), the Von Mises stress and the equivalent plastic strain distribution in the course of the SPT test were calculated. The stress distribution is quite uniform along the notched sample (Figure 12 a) but, nevertheless, strain amplifies in two symmetrical regions separated from the centre of the notch (Figure 12 b).
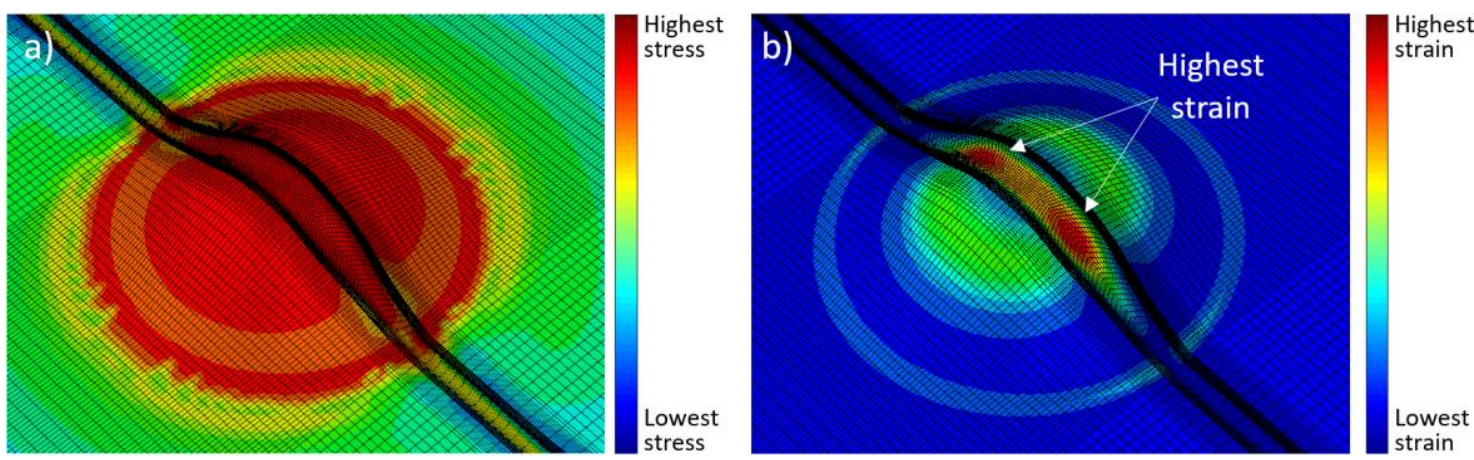

Figure 12. Numerical simulation. a) Stress distribution; b) strain distribution

Using again the two extreme steels (S355 and WM), the location of the first cracks in the notch was determined under SEM observation. Figures 13 and 14 show the crack initiation location in S355 and WM steels respectively. In both the steel with the highest and that with the lowest fracture toughness, cracks initiated in the region of the sample submitted to the maximum strain. 


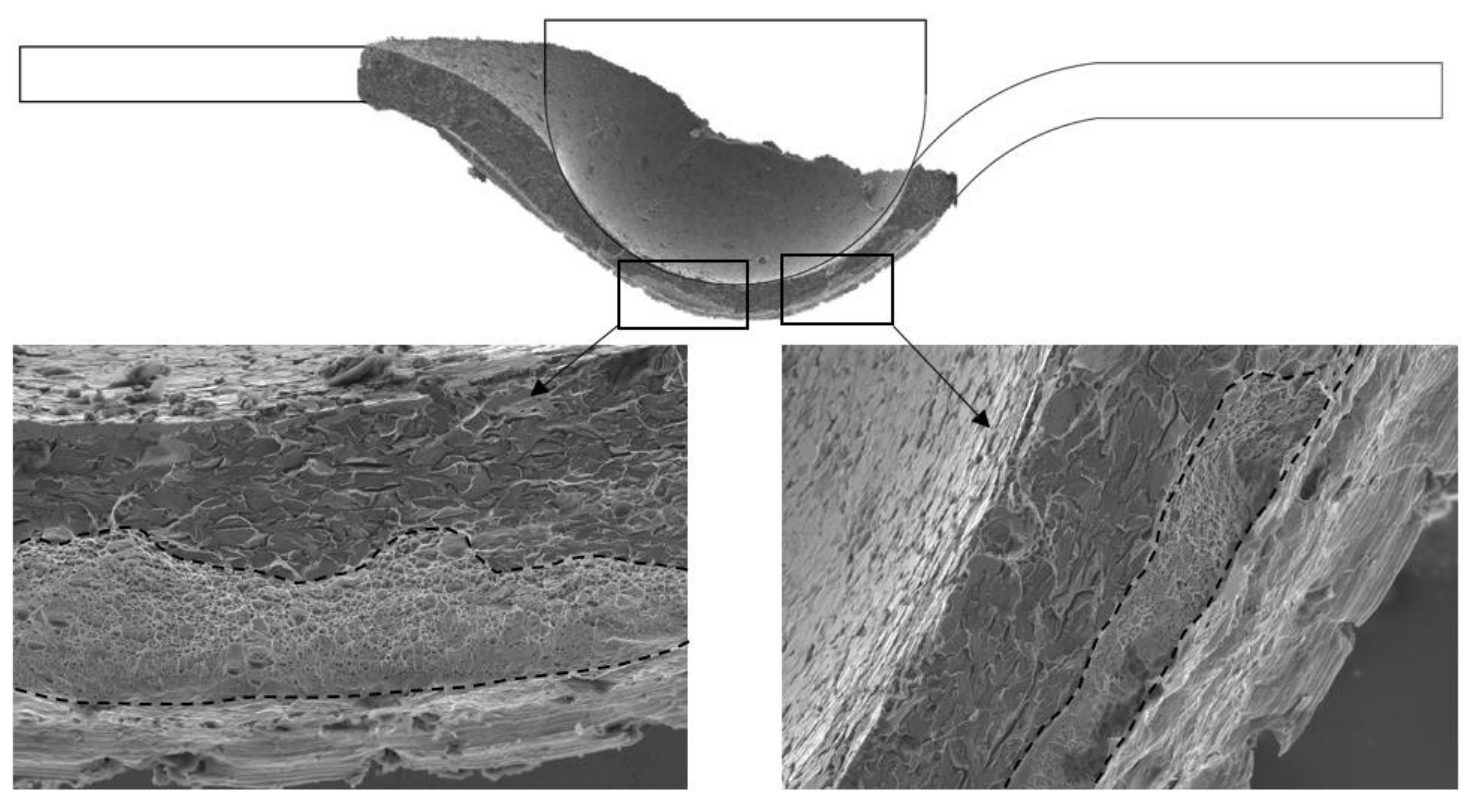

Figure 13. Crack initiation location in S355 notched SPT sample

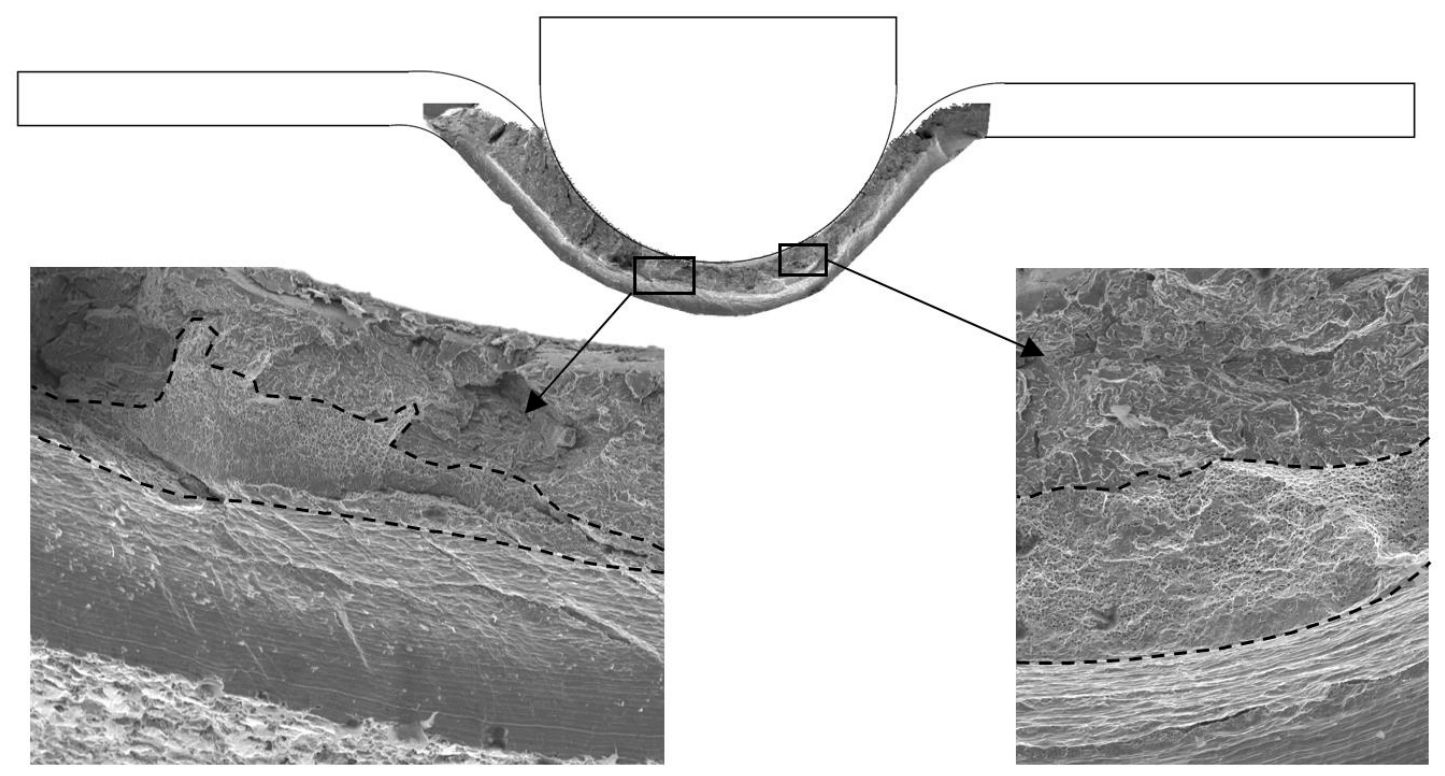

Figure 14. Crack initiation location in WM notched SPT sample

\section{CONCLUSIONS}

The methodology to obtain the $J_{I C}$ and $\delta_{I C}$ elasto-plastic fracture toughness parameters by means of testing notched SPT samples is described in this paper.

It has been numerically demonstrated that significant modifications of the mechanical properties of steels and slight changes in the thickness of longitudinally notched SPT specimens have a negligible influence on the relationship between the notch width enlargement, $\delta_{S P T}$, and the punch displacement measured in these tests. Moreover, careful SEM observations of interrupted SPT tests has led to two significant conclusions. Firstly, the separation between the experimental and numerical SPT curves define the initiation of cracking. Secondly, the first cracks are always located in the notch sample region submitted to the maximum strain.

As fracture toughness tests were also performed on standard specimens, a relationship between the CTOD at initiation of crack growth and the notch width enlargement measured at the maximum punch displacement of the SPT samples was finally obtained for this specific specimen geometry. 


\section{REFERENCES}

[1] ASTM E 1820-01: Standard Test Method for Measurement of Fracture Toughness, 2001. doi:10.1520/E1820-09.2.

[2] I.I. Cuesta, C. Rodríguez, T.E. García, J.M. Alegre, Effect of confinement level on mechanical behaviour using the small punch test, Eng. Fail. Anal. 58 (2015) 206-211. doi:10.1016/J.ENGFAILANAL.2015.09.008.

[3] T.E. García, C. Rodríguez, F.J. Belzunce, C. Suárez, Estimation of the mechanical properties of metallic materials by means of the small punch test, J. Alloys Compd. 582 (2014) 708-717. doi:10.1016/J.JALLCOM.2013.08.009.

[4] P.M. Bravo Díez, M. Preciado Calzada, D. Cárdenas Gonzalo, J. Calaf Chica, Change of mechanical properties of AM60B alloy with heat treatments and its correlation with small punch tests, Theor. Appl. Fract. Mech. 86 (2016) 101-108. doi:10.1016/J.TAFMEC.2016.09.014.

[5] B. Arroyo, J.A. Álvarez, R. Lacalle, Study of the energy for embrittlement damage initiation by SPT means. Estimation of KEAC in aggressive environments and rate considerations, Theor. Appl. Fract. Mech. 86 (2016) 61-68. doi:10.1016/J.TAFMEC.2016.08.019.

[6] S. Yang, J. Zhou, X. Ling, Z. Yang, Effect of geometric factors and processing parameters on plastic damage of SUS304 stainless steel by small punch test, Mater. Des. 41 (2012) 447-452. doi:10.1016/J.MATDES.2012.05.029.

[7] T.D. Shikalgar, B.K. Dutta, J. Chattopadhyay, Assessment of fracture resistance data using p-SPT specimens, Theor. Appl. Fract. Mech. 98 (2018) 167-177. doi:10.1016/J.TAFMEC.2018.10.003.

[8] S. Tenneti, P.V. Durgaprasad, N. Naveen Kumar, S.K. Bonagani, J. Chattopadhyay, I. Samajdar, V. Kain, Detection of embrittlement in low alloy steels due to thermal aging by small punch test, Mater. Sci. Eng. A. 759 (2019) 181-194. doi:10.1016/J.MSEA.2019.05.009.

[9] A. Ortiz-Mariscal, M.L. Saucedo-Muñoz, Naveena, S. Komazaki, Application of small punch creep testing for evaluation of creep properties of as-received and artificially aged 5Cr-0.5Mo steel, Mater. Sci. Eng. A. 709 (2018) 322-329. doi:10.1016/J.MSEA.2017.10.060.

[10] S. Holmström, Y. Li, P. Dymacek, E. Vacchieri, S.P. Jeffs, R.J. Lancaster, D. Omacht, Z. Kubon, E. Anelli, J. Rantala, A. Tonti, S. Komazaki, Naveena, M. Bruchhausen, R.C. Hurst, P. Hähner, M. Richardson, D. Andres, Creep strength and minimum strain rate estimation from Small Punch Creep tests, Mater. Sci. Eng. A. 731 (2018) 161-172. doi:10.1016/J.MSEA.2018.06.005.

[11] L.-Y. Wang, Z.-M. Song, X.-M. Luo, G.-P. Zhang, 3D X-ray tomography characterization of creep cavities in small-punch tested 316 stainless steels, Mater. Sci. Eng. A. 724 (2018) 69-74. doi:10.1016/J.MSEA.2018.03.048.

[12] C. Rodríguez, D. Arencón, J. Belzunce, M.L. Maspoch, Small punch test on the analysis of fracture behaviour of PLA-nanocomposite films, Polym. Test. 33 (2014) 21-29. doi:10.1016/j.polymertesting.2013.10.013.

[13] C. Quintana, C. Rodríguez, F.J. Belzunce, A.C. Caballero, C. Baudín, Ceramic materials characterization using miniature mechanical tests: comparison between B3B and SPT tests, J. Eur. Ceram. Soc. (2019). doi:10.1016/J.JEURCERAMSOC.2019.06.019.

[14] T. Abt, G. Álvarez, C. Rodríguez, M.L. Maspoch, Using the small punch test to analyse the influence of ultraviolet radiation on the mechanical behaviour of recycled polyethylene terephthalate, J. Strain Anal. Eng. Des. (2019) 1-7. doi:10.1177/0309324719833237.

[15] D. Andrés, P. Dymáček, Study of the upper die clamping conditions in the small punch test, Theor. Appl. Fract. Mech. 86 (2016) 117-123. doi:10.1016/J.TAFMEC.2016.07.012.

[16] P. Dymáček, Recent developments in small punch testing: Applications at elevated temperatures, Theor. Appl. Fract. Mech. 86 (2016) 25-33. doi:10.1016/J.TAFMEC.2016.09.013.

[17] R.J. Lancaster, W.J. Harrison, G. Norton, An analysis of small punch creep behaviour in the $\gamma$ titanium aluminide Ti-45Al-2Mn-2Nb, Mater. Sci. Eng. A. 626 (2015) 263-274. 
doi:10.1016/J.MSEA.2014.12.045.

[18] R.J. Lancaster, S.P. Jeffs, H.W. Illsley, C. Argyrakis, R.C. Hurst, G.J. Baxter, Development of a novel methodology to study fatigue properties using the small punch test, Mater. Sci. Eng. A. 748 (2019) 21-29. doi:10.1016/J.MSEA.2019.01.074.

[19] Afnor, ECISS/TC 101 “Small Punch Test Method for Metallic Materials,” AFNOR, 2019.

[20] P. Kumar, B.K. Dutta, J. Chattopadhyay, Fracture toughness prediction of reactor grade materials using pre-notched small punch test specimens, J. Nucl. Mater. 495 (2017) 351-362. doi:10.1016/J.JNUCMAT.2017.08.035.

[21] E. Martínez-Pañeda, T.E. García, C. Rodríguez, Fracture toughness characterization through notched small punch test specimens, Mater. Sci. Eng. A. 657 (2016) 422-430. doi:10.1016/j.msea.2016.01.077.

[22] I.I. Cuesta, C. Rodriquez, F.J. Belzunce, J.M. Alegre, Analysis of different techniques for obtaining pre-cracked/notched small punch test specimens, Eng. Fail. Anal. 18 (2011) 2282-2287. doi:10.1016/j.engfailanal.2011.08.004.

[23] X. Mao, M. Saito, H. Takahashi, Small punch test to predict ductile fracture toughness JIC and brittle fracture toughness KIC, Scr. Metall. Mater. 25 (1991) 2481-2485. doi:10.1016/0956716X(91)90053-4.

[24] X. Mao, H. Takahashi, T. Kodaira, Estimation of mechanical properties of irradiated nuclear pressure vessel steel by use of subsized CT specimen and small punch specimen, Scr. Metall. Mater. 25 (1991) 2487-2490. doi:10.1016/0956-716X(91)90054-5.

[25] R. Hurst, Y. Li, K. Turba, Determination of fracture toughness from the small punch test using circular notched specimens, Theor. Appl. Fract. Mech. 103 (2019) 102238. doi:10.1016/J.TAFMEC.2019.102238.

[26] K. Turba, B. Gülçimen, Y.Z. Li, D. Blagoeva, P. Hähner, R.C. Hurst, Introduction of a new notched specimen geometry to determine fracture properties by small punch testing, Eng. Fract. Mech. 78 (2011) 2826-2833. doi:10.1016/J.ENGFRACMECH.2011.08.014.

[27] J.M. Alegre, R. Lacalle, I.I. Cuesta, J.A. Álvarez, Different methodologies to obtain the fracture properties of metallic materials using pre-notched small punch test specimens, Theor. Appl. Fract. Mech. 86 (2016) 11-18. doi:10.1016/J.TAFMEC.2016.09.006.

[28] B. Arroyo, J.A. Álvarez, R. Lacalle, P. González, Using Small Punch tests in environment under static load for fracture toughness estimation in hydrogen embrittlement, (n.d.).

[29] T.E. García, C. Rodríguez, F.J. Belzunce, I.I. Cuesta, Development of a new methodology for estimating the CTOD of structural steels using the small punch test, Eng. Fail. Anal. 50 (2015) 8899. doi:10.1016/j.engfailanal.2015.01.011.

[30] E. Cárdenas, F.J. Belzunce, C. Rodríguez, I. Peñuelas, C. Betegón, Application of the small punch test to determine the fracture toughness of metallic materials, Fatigue Fract. Eng. Mater. Struct. 35 (2012) 441-450. doi:10.1111/j.1460-2695.2011.01635.x.

[31] CEN, EN ISO 6892-1 Metallic materials — Tensile testing Part 1: Method of test at room temperature, 2016. doi:10.3403/30268532.

[32] E. Martínez-Pañeda, I.I. Cuesta, I. Peñuelas, A. Díaz, J.M. Alegre, Damage modeling in Small Punch Test specimens, Theor. Appl. Fract. Mech. 86 (2016) 51-60. doi:10.1016/J.TAFMEC.2016.09.002.

\section{Acknowledgments:}

The authors would like to thank the Spanish Ministry of Economy and Competitiveness for the funding received to carry out research project RTI2018-096070-B-C31. Authors also thank the financial support received from the Principado de Asturias government through the FC-GRUPIN-IDI/2018/000134 project. Our thanks also to the Scientific and Technical Service, University of Oviedo, for the use of the SEM JEOLJSM5600 scanning electron microscope. 